\title{
Research, Sport, and Higher Education: An Introduction to the Journal of Intercollegiate Sport
}

\section{R. Scott Kretchmar}

This has been a year for firsts - the first Scholarly Colloquium at an NCAA convention, and now, the first research journal devoted specifically to collegiate sport. ${ }^{1}$ As with most new ventures, hopes for success are running high.

In this case, the hopes run in at least two directions. The first is based on the value of knowing more about intercollegiate sport. This knowledge-for-its-ownsake, liberal-arts motive is probably as old as scholarship itself. We are a curious people. We believe that understanding something is better than living in ignorance. We like to unravel complex cause-and-effect relationships, look for underlying mechanisms, and better see the big picture. Thus, whether or not scholarship on intercollegiate sport leads to anything useful, there is a certain value that comes with understanding itself, with knowing more about the world and our lives in it. ${ }^{2}$

It would be incorrect to say that we do not also have very practical goals in mind for both the Colloquium and the Journal. These objectives are related to past, current, and future efforts at integrating intercollegiate athletics with the core purposes and values of higher education. All Journal of Intercollegiate Sport (JIS) Board members are educators who care about the integrity of higher education. In this sense, our efforts are related to the current reform movement promoted by such organizations as the Faculty Athletics Representatives Association (FARA), the Coalition for Intercollegiate Athletics (COIA), the Knight Foundation, and the NCAA itself under the leadership of Myles Brand. We believe that effective reform efforts, from whatever source or constituency they might emerge, require good information.

Some of this information is already in hand. We are certainly not the first group of scholars who have been interested in studying college sport, and this journal is certainly not the first publication to contain reform-relevant research. Nevertheless, it also seems to be true that college sport, given its centrality and influence in American culture and higher education, has been given less attention than it is due.

A look at several mainline journals devoted to the topic of sport and culture provides support for this claim. Over the past 10 years, these publications, with only a couple of exceptions, have given little more than passing attention to intercollegiate athletics. Below is a sample list of journals followed by a count of the total number of articles on college sport included in that journal over the entire 10-year period.

The author is the Editor of the Journal of Intercollegiate Sport and is with Penn State University, University Park, PA. 
Journal of Sport and Social Issues (2)

Journal of Sport and Exercise Psychology (2)

Sociology of Sport (9)

Sport History Review (4)

Research Quarterly for Exercise and Sport (10)

Journal of the Philosophy of Sport (1)

Journal of Sport Behavior (30)

\section{Journal of Sport Management (35)}

These data show that a little more than one article a year, on average, has been published in these journals on the phenomenon of intercollegiate sport. By almost any standard, this is a poor record. Even though there might be good reasons for avoiding or ignoring this topic (see, for example, the essay by Jay Coakley in this volume), and even though some of the generic research on sport in these and other journals is applicable to college athletics, the fact remains that researchers, for whatever reason, are attending mostly to other matters. In addition, many of these matters appear to have far less cultural visibility and significance than sport. In short, the specific issue of high-level, organized athletic competition sponsored by institutions of higher education is receiving relatively little research scrutiny.

The lack of attention paid to intercollegiate sport rides on the shoulders of an even more fundamental condition that affects the quantity and quality of research on athletics. Topics related to intercollegiate athletics - among them, sport, games, play, competition, physical education, and embodiment-do not have the intellectual cachet enjoyed by many other topics.

In my own discipline, card-carrying philosophers with an interest in sport would often remain closeted to protect their own reputations. They would attend our philosophy of sport meetings without informing their department heads, and some even chose not to include citations of their refereed articles on sport in their year-end reports and resumes.

The sport-related discipline of Kinesiology is also seen to lie on the periphery of academic legitimacy. For many years the National Research Council (NRC) refused to include Kinesiology among its recognized research fields. Its rationale was this: Any discipline that is focused on physical activity, sport, and the body had to be, by definition, a professional field, one that is dedicated to promoting only such matters as successful coaching, fitness enhancement, and physical education instead of generating knowledge about an important aspect of the human condition. ${ }^{3}$

Perhaps this broader neglect of sport and "things physical" is related to the lingering effects of mind-body dualism, or to distinctions between high versus low or popular culture, or to long-standing academic traditions that separate intellectual procedures like writing from motor acts like hitting a tennis ball, or even more fundamentally to epistemological commitments that favor theory or "knowing that" over practice or "knowing how" (Kretchmar, 2005). In all likelihood, several of these factors working together account for the academy's relative neglect of sport as a theme for scholarly inquiry.

These speculations could be carried further, but they are probably better saved for another time. The important point for our purposes here is that, whatever the 
cause or causes of neglect, more and better research is needed-specifically on the topic of college sport.

By way of contrast, strong opinions about the status of intercollegiate athletics - both pro and con—are not difficult to find. They fill our newspapers, tabloids, chat-room agendas, and any number of popular books. It is interesting to note that even the more careful and data-driven analyses of intercollegiate athletics, such as those of Shulman and Bowen (2001) and Bowen and Levin (2003), are brought up short by the lack of solid information and might even be slanted in the direction of prior ideological commitments. ${ }^{4}$ It is also interesting to note that many books and articles on college sport tend to be polemical in nature. That is, they are argumentative and unduly enthusiastic and optimistic or overly critical and pessimistic. Such extreme positions feed on many things, but one of them is a lack of good information.

There is no question that, on occasion, extreme positions are warranted by the facts and by ethical concerns over such matters as harm and social injustice. However, polemics, dialectic, or any procedure that attempts to divide things neatly into hard and fast dichotomies runs a risk of oversimplification.

C.P. Snow (1959/1986) of "two cultures" fame was apologetic about his own attempts to describe two seemingly incompatible cultures - those of the sciences and the humanities: "The number 2 is a very dangerous number: that is why dialectic is a dangerous process. Attempts to divide anything into two ought to be regarded with much suspicion" (p. 64).

Gould (2003) is even more blunt than Snow in underlining problems often associated with polemics. He wrote that dualisms of any sort constitute "the simplistic imposition of phony dichotomous models upon a much different, and far more subtle, story of substantial and fruitful interaction" (p. 83-84). He argued, in effect, that complex phenomena like college sport traffic in the realm of ambiguities, paradoxes, differences by degree, tendencies, mixtures, tensions, complexes, transitions, and all other forms of messiness. In this view, good research helps us avoid the (often) unhelpful extremes. Similarly, the lack of good research could delay any move toward the more fruitful, but often more ambiguous, middle.

Even if this is the case, more and better research on college sports is not a panacea for reducing inappropriate extremism. Polemical discourse, as we have seen in politics and elsewhere, enjoys a degree of independence from the research or "facts" on which it often purports to rest. Zealous critics and enthusiastic apologists alike defend extreme positions by citing data selectively, interpreting data in ways that favor their position, exaggerating, lying, and following one line of logic when others are equally plausible, or in some cases, all of them at once.

We have all read accounts by supporters and nay-sayers alike that are heavily colored by idiosyncratic experiences, emotion, anecdotal information, and seemingly often too by, what are for them, unimpeachable antecedently formed convictions. Extreme critics are convinced that big-time college sport is thoroughly corrupt and, at least in anything like its current form and with current economic and social forces at play, without any hope of redemption. Likewise, some proponents of intercollegiate athletics are absolutely sure that, at least on balance, sports do far more good than harm. Inherent structural dangers are overlooked and scandals are excused either as anomalies or stories exaggerated beyond their merits by excessive media attention. It appears that little could transpire for residents of either camp that 
would, or even could, change their minds. This should be troubling for any of us who believe that good research and information should affect attitudes, policies, and actions - and that even the most stubborn among us can change.

Something as complex as intercollegiate sport will undoubtedly present some issues that can be dichotomized or otherwise conceptualized in terms of limited options. Sport can also be expected to show a face that requires more complex treatment. Such research might, for example, acknowledge degrees of good and harm; identify those areas meriting support, others requiring reform, and yet others deserving elimination; underline the complex similarities and differences between athletic operations and activities in the rest of the university; and examine differences between sports, between different kinds of institutions, and among diverse levels of competition. This approach would require a careful "look and see" policy to determine whether the status quo is to be supported, partly supported, or not supported at all. These "in-between" kinds of positions that acknowledge that matters are more complex then they are often made out to be, however, do not fare very well either when good information is missing or when the mood of the time pushes both proponents and critics of intercollegiate sport toward the extremes.

One of the challenges faced by myself and other Board members is related precisely to these conditions-namely, missing information and the polemical spirit of the times. In launching the Colloquium and the Journal, we are aware of the importance of exercising good judgment in promoting research that, on the one hand, does not shy away from controversy, but on the other, does not generate more heat than light. We harbor no delusions about the existence of pat formulas that will make this task an easy one. Neither do I nor, presumably, any other Board members involved with the Colloquium or Journal enjoy any privileged perspective from which to make determinations in this regard.

To speak for myself, I am certainly embedded in my own history as a Faculty Athletics Representative and the father of a daughter who, a number of years ago, played Division I basketball. Decades ago (and I hesitate to say how many) I lettered in three sports at a Division III liberal arts institution in the Midwest. As a more-or-less pragmatic, anthropological, and phenomenologically tending sport philosopher, I embrace some of the hopes and commitments of folks like John Dewey, William James, and Maurice Merleau-Ponty. I do not much like asomatic, analytic analyses, and I worry about the agendas of those involved in linear, reductionistic science. So, I plead guilty as charged to any suggestion that I am predisposed and otherwise tainted.

Other Board members, all of them distinguished scholars, also bring with them a variety of personal and professional relationships to intercollegiate sport-as athletes, as faculty members from different parts of the country and institutions with different missions, as scholars from various disciplines, even as occasional apologists for and critics of intercollegiate athletics.

Thus, without the perfect vision provided by an Archimedean point of reference, all of us on the Board have to exercise as much objectivity as we can muster, serve as a multiple checks-and-balance system for the excesses of one another, and ultimately fall back, as best we can, on broadly accepted tenets of good scholarship. I will say more about this later when discussing policies and procedures for submitting articles to JIS. 


\section{Research, Athletic Reform, Optimism, and Pessimism}

The mission of our organization is clearly stated in our bylaws-namely, "to stimulate, encourage, and promote study, research, and writing related to intercollegiate athletics; to demonstrate the relevance of research for reform efforts in intercollegiate athletics; to support core values of higher education in relationship to intercollegiate sport; to organize and conduct an annual scholarly colloquium; to sponsor a scholarly journal; and to support and cooperate with local, national, and international organizations of similar purpose." Inherent in this statement is a degree of optimism-optimism about the utility of research, opportunities for change, and the potentially fruitful interplay between athletics and education.

Many of you know that reform efforts have been around for a long time. Since the founding of the NCAA in 1906, a number of reformers and reform movements have attempted to affect the future of intercollegiate athletics. Among the most notable attempts have been the Carnegie Foundation Report on Higher Education in 1929, the American Council on Education's (ACE) report on athletic policy in 1952, George Hanford's ACE recommendation for a national study of intercollegiate athletics in 1974, and the report of the Knight Commission on Intercollegiate Athletics in 1991.

A recurring theme in these efforts has been presidential control-specifically, that presidents more than any other individual or group of individuals are in a position to reign in excesses in their athletic programs. Arguably, however, these and other reform efforts have had only negligible effect (Thelin, 1994). In fact, the Knight Commission reconvened in 2001 and issued a second report that suggested, among other things, that presidents during the preceding 10 years had failed to exercise meaningful control.

This history of modest gains or utter failure, depending on one's perspective, could lead to cynicism and resignation. This history could also suggest that the call for more and better research on intercollegiate athletics for purposes of reform is idealistic and otherwise naive.

I cannot speak for all Board members, but if optimism brings with it a degree of idealism and naivete, I accept that as a fair criticism. It is important, however, to reemphasize the point that research is not a panacea for reform. Although research might be a necessary component of effective change, it is certainly not also sufficient. It is not sufficient because social change requires commitment, energy, resolve, courage, organized intervention, social pressure, political strategies, strong leaders, and more-matters that far transcend the Board's purposes and abilities and factors over which we have little control. Nevertheless, efforts to replace hypotheses, suppositions, impressions, biases, and even, on occasion, heated polemics with solid information and reasoned dialog are not trivial tasks. If current reform efforts are to persist, and persist to good effect, research will need to play a central role.

\section{A Brief History of the Colloquium and Journal}

In 2006, the President of the NCAA, Myles Brand, began work on sponsoring a colloquium. A call for papers went out and some of us, myself included, responded by submitting abstracts. The quality and quantity of submissions, however, proved 
to be inadequate, and Dr. Brand did not want to initiate such a project unless it was going to be done well. This is where the Board comes in.

When I became involved in the project, I indicated to President Brand that I wanted the best researchers I could recruit to design the colloquium and serve as the editorial board for the new journal. He agreed.

I could not have hoped for greater success. I had virtually a $100 \%$ rate of acceptance when I invited a variety of scholars - individuals who were already very busy - to join the Board. This is not the right place to detail their individual achievements, but in a word, I looked for the top people in their respective fields. Some I knew personally; others I knew by reputation only.

These individuals collectively have written dozens of books, hundreds of book chapters, and thousands of refereed articles. Most of them have been elected Fellows in the academies related to their disciplinary and professional expertise. Many of them have won prestigious awards or have been asked to sit on equally prestigious boards. All of them are known and respected internationally by their peers for the quality of research they have produced during their careers. I think it is important to add that all of them are interested in sport-college sports. Moreover, they are interested in making college sports better. In the final analysis, I think that is why they agreed to join the Board and add yet one more duty to their already crowded schedules. A listing of the current Board members with their institutional affiliations and their areas of scholarly expertise is shown in Table 1.

Board members convened for the first time at the 2007 NCAA convention in Orlando, Florida. At that meeting we agreed to develop a day-and-a-half program for the Nashville convention that would consist of four plenary speakers with two reactors for each. The conference theme would be based on a rhetorical question: "Intercollegiate Sport: A Legitimate Focus for Scholarly Inquiry?" Although most of us felt that we could already answer affirmatively, we did not want to jump ahead of ourselves on a foundation of unnecessarily optimistic assumptions.

The four plenary articles and eight reactions included in this volume, I believe, speak to the wisdom of that decision. They address practical difficulties in conducting research, the problem of different conclusions being drawn from the same data, relationships between research and athletic reform, and the cash value of university-specific data in driving policy and procedures.

We also chose to limit the program to invited presentations only. Although this decision was not made lightly, and we understood that it would carry both costs and benefits, we wanted to make sure-above all else-that the first colloquium got off to a good start. Thus, we identified keynote speakers with a long and distinguished history of top-level scholarship in the area of sport and intercollegiate athletics. We also invited reactors who had comparably impressive resumes. This was all done with the understanding that the Journal would be open to submissions from any and all scholars and that future Colloquia would also have sessions for unsolicited papers.

My hope is that many of you reading this journal, both junior and senior scholars alike, will apply your own research skills to intercollegiate sport or, if you have already been working in that area, submit your research to the Journal. The Journal is both interdisciplinary and cross-disciplinary. This means, on the one hand, that we will accept solid research articles from the sciences, social sciences, humanities, and professions - as long as they address sport and intercollegiate athletics. 


\section{Table 1 Current Board Members, Their Affiliations, and Areas of Expertise}

\begin{tabular}{lll}
\hline Ketra Armstrong & $\begin{array}{l}\text { California State } \\
\text { University, Long Beach }\end{array}$ & $\begin{array}{l}\text { Sport Management, } \\
\text { Finance }\end{array}$ \\
& $\begin{array}{l}\text { University of North } \\
\text { Carolina, Chapel Hill }\end{array}$ & Ethics, Sport Philosophy \\
Dana Brooks & $\begin{array}{l}\text { University of West } \\
\text { Virginia }\end{array}$ & $\begin{array}{l}\text { Sport Education, } \\
\text { Sociology of Sport }\end{array}$ \\
Packianathan Chelladurai & The Ohio State University & Sport Management \\
Jane Clark & University of Maryland & Motor Development \\
Jay Coakley & University of Colorado & Sport Sociology \\
& (emeritus) & \\
Kirk Cureton & University of Georgia & Exercise Physiology \\
John (Jack) Evans & University of North & Business \\
Carolina, Chapel Hill & \\
Matt Mitten & Marquette University & Sport Law \\
Malcolm Moran & Penn State University & Sport Journalism \\
William J. Morgan & University of Southern & Ethics, Sport Philosophy \\
California & \\
Robert Simon & Hamilton College & Ethics, Sport Philosophy \\
John Thelin & University of Kentucky & Higher Education \\
Daniel Wann & Murray State University \\
Maureen Weiss & Spiversity of Minnesota & Spychology \\
& Sport Psychology, \\
& & Child Development \\
\hline
\end{tabular}

Articles that emerge from medicine or physiology, from sport journalism or sport law, from sociology or philosophy, for example, are equally welcome. This is the interdisciplinary aspect of the Journal.

On the other hand, we are also hoping to have submissions that focus on complex issues and that transcend traditional academic boundaries. For example, someone might write on fan behavior and use information from sociology, psychology, sport management, and ethics in coming to conclusions or recommendations. The focus, in other words, would be on the problem, not the discipline from which answers to the problem might emerge. This is the cross-disciplinary focus of the Journal.

On the issue of potentially controversial scholarship, we want to be very clear. The Board welcomes good research that would tend either to support current practice or challenge the status quo. The central issue is not where the research falls on the political landscape but what the quality of that work is. Thus, the presence or absence of controversy is, and should be, a byproduct of this commitment to quality, not an objective. Consequently, we do not intend to publish editorials, polemical essays, or any other articles that are designed to inflame or arouse more than enlighten. 
Here is how we attempted to word these various objectives and commitments in our "Submission Guidelines":

The Journal of Intercollegiate Sport (JIS) welcomes a broad range of scholarly submissions related to sport in the context of higher education. Contributions may be specifically about sport in college or university settings or about broader biological, medical, psychological, social, or philosophical factors that impact sport in higher education. Articles from the sciences, social sciences, humanities, and professional fields will be accepted. Submissions that are cross-disciplinary in nature and have practical applications are encouraged.

Articles should be written for an educated, lay readership and must be nontechnical in nature. Accordingly, they should address topics of general interest and be free of field-specific jargon.

Standard canons of good research will be honored in the review process. Depending on the type of research being conducted, submissions must reflect good scientific procedures, the best practices of qualitative methodologies, and/or sustained and effective argumentation. Submissions that are primarily editorial or polemical in nature rather than scholarly are not consistent with the mission of the Journal. On the other hand, well-research and argued essays that either challenge or support the status quo in intercollegiate sports are welcome.

\section{Introduction to Volume 1, Number 1}

This volume is a collection of four plenary articles and eight reactions read at the first Scholarly Colloquium on Intercollegiate Sport held in conjunction with the NCAA Annual Convention, January 6-8, 2008, in Nashville, Tennessee. It also includes a bibliography of recent and classical research on intercollegiate athleticsresearch that comes from the sciences, social sciences, and humanities, as well as such professional fields as sport management, sport law, and sport journalism.

The theme for the Colloquium, as noted, focused on the legitimacy of intercollegiate sport as an area for scholarly inquiry. The first article was authored by Jay Coakley, a noted sport sociologist. In this essay, he does not take issue with any claims about the legitimacy of sport-related research or with the fact that it is needed. Rather he argues that faculty have a number of disincentives for directing their efforts in this direction. He describes four "sites" at which difficulties can be encountered: the university, academic disciplines, local communities, and the NCAA. He raises questions about bias, ideology, and objectivity, and argues that the "culture gap" between athletics and academics must be narrowed if research is to have any meaningful impact. He closes with recommendations for increasing incentives for faculty to engage in sport-related research.

Jack Evans, the first reactor, is the Hettleman Professor of Business at the University of North Carolina, Chapel Hill. He takes a more optimistic view of the situation and cites two examples from the world of business in which research had a positive impact on corporate success and in which initially unwelcome research scrutiny had a rapid and positive effect. From his experience as a long-time Faculty 
Athletics Representative, Evans applauds Coakley's recommendations for increasing sport-related research and suggests that the NCAA and its own research team can contribute to this outcome.

Margaret Duncan, a professor of sport sociology from the University of Wisconsin-Milwaukee, finds herself in substantial agreement with Coakley's points and provides several anecdotes related to the cultural divide between the athletic and academic sides of the house. She takes issue, however, with Coakley's pessimism about the esteem in which sport- and body-related research is held throughout much of the university. She argues that any number of departments have adopted the topic of "body culture" as their own.

Robert Simon, the second keynote speaker, is the Marjorie and Robert W. McEwen Professor of Philosophy at Hamilton College. He has written extensively on the ethics of sport and offers an article that is cautiously optimistic in tone. He argues that critics of sport often import negative agendas to their research. They emphasize the least friendly interpretation of sport-education relationships, even though other more positive and equally plausible explanations are available. He concludes that not only is it unclear that athletics undermine academics, but it might be the case that sport involvement reinforces the values and objectives of higher education.

One of his reactors, Bill Morgan, a professor and well-published sport philosopher from the University of Southern California, takes issue with many of Simon's claims. Although acknowledging that he might be right about sport at the Division III level, Morgan argues that Simon's optimism is not warranted in Division I athletics - and particularly not in the domains of football and men's basketball. In those places, according to Morgan, business logic and market forces hold sway, and those influences are typically not compatible with the purposes of higher education.

Drew Hyland, the second reactor to Simon's paper, holds the Charles A. Dana Chair of Philosophy at Trinity College in Hartford, Connecticut. Chiding Simon for his timidity in arguing that sport might be compatible with the purposes of higher education, Hyland argues that the ancient Greeks made more aggressive claims about the worth of sport and provided a model that includes "athletic development [as] a significant element in a truly humane and liberal education." Rather than separating athletics and academics for purposes of mutual protection, Hyland suggests that the two should be brought closer together. He provides examples of how this might be done.

John Thelin, a University Research Professor and a member of the Educational Policy Studies faculty at the University of Kentucky, headed up the third plenary session. He cautions that much literature and research on intercollegiate athletics is extremist in nature - both for and against what he calls "this Peculiar Institution" that seems to enjoy "benefits of a special zoning ordinance within the campus." He reviews previous attempts at reform that would eliminate or reduce the harmful effects of this "ordinance" and suggests that neither faculty nor presidents, but rather trustees, may hold the keys to progress in this regard.

Malcolm Moran, the first reactor in this session, holds the Knight Chair in Sports Journalism at Penn State University. From his experience as a 30-year journalist, he provides a number of anecdotes about coaches and athletes and their place in the university. He sees divisions between traditional journalistic 
responsibilities (e.g., different methods and procedures for interviewing college versus professional athletes or covering "Saturday" versus "Sunday" football) breaking down and creating ambiguities about the character of college sports.

Janet H. Lawrence, the second reactor to Professor Thelin's article, is an Associate Professor of Higher Education at the University of Michigan. As lead researcher on a recent study of faculty perceptions of intercollegiate athletics funded by the Knight Foundation, Lawrence reviews Thelin's claim that faculty are unlikely to be major players in any athletic reform movement. Using data from the Faculty Survey, Lawrence provides empirical support for many of Thelin's claims, including statistics on the low priority given to athletics in faculty governance. Her research also shows how faculty perceptions are variable and closely related to local conditions and perspectives.

Mary Jo Kane, professor and chair in the School of Kinesiology and Director of the Tucker Center for Research on Girls and Women in Sport at the University of Minnesota, was the final plenary speaker. The research of Dr. Kane was commissioned by Robert Bruininks, President of the University. Kane, with the assistance of Perry Leo and Lynn Holleran, presents those findings-including longitudinal data on admissions policies and measures of student-athlete academic progress, current policies and best practices related to academic support, and strategies designed to improve academic success, most notably those that enhance persistence and graduation. An innovative statistical regression model is used to identify measures of academic success and failure.

The first reactor was Packianathan Chelladurai, a professor at The Ohio State University and a well-known researcher and doctoral mentor in the area of sport management. He reviews a number of Professor Kane's and Leo's findings but focuses on one particular assumption of this research—namely, that athletics occurs "in" education rather than "as" education. He underlines a number of inconsistencies found in our universities in how performance is valued, taught, and incorporated into the curriculum. In line with his arguments for athletics as education, he suggests that institutions develop a College of Sports.

The final reactor was Carolyn Callahan, a professor in the Curry School of Education at the University of Virginia and Director of the National Research Center on the Gifted and Talented. She calls the Kane, Leo, and Holleran article a "benchmark paper" and applauds them for sharing their results publicly. She reviews some of the most significant decisions made by the research team and underlines key results. She also offers a number of suggestions for strengthening future research efforts - some of them related to research design, others to proposed solutions and policy decisions.

\section{Summary}

As important as each one of these four keynote addresses and eight reactions is in its own right, together they generate important themes and questions. As you read through the individual articles, it might be useful to keep these broader issues in mind. I have attempted to list several of them here. 


\section{Issue \#1: The Likelihood of More and Better Research Being Produced}

The speakers at this Colloquium are all veteran researchers. It would stand to reason that they would see the scholarly study of intercollegiate athletics as both legitimate and important. Researchers will not, however, turn their attention to sport on principle alone. Other conditions, such as those bearing on promotion and tenure, the availability of subjects, funding, the perceived significance of sport, and so on, need to be in place before any dramatic increase in research is likely to take place.

We might ask, are such conditions in existence or not? Are we, or are we not, at a moment in history when college sport will become a more legitimate topic for scholarly inquiry?

\section{Issue \#2: Athletics as Similar to or Dissimilar From the Rest of the Institution}

Speakers also touched on another nettlesome issue that can dramatically affect perceptions of intercollegiate athletics and their worth. Some see athletics largely as a reflection of the university, its policies, and its commitments. Even the commercialization of sport must be seen, in this view, as relatively unsurprising given the current business interests and practices of the larger university. In short, athletic operations are analogous to proceedings in the rest of the institution and accordingly, do not merit inordinate attention. Others, however, see athletics as very different in degree or kind from the institutions in which they are housed. Ground rules for athletes and athletics are not the same as those that apply elsewhere in higher education. From this perspective, "different zoning ordinances" for athletics should be at least a potential cause for serious concern and action.

Which side is closer to the truth? Is the evolution of athletics more a reflection of changes in the institution itself, or does athletics march to a different drummer? What are we to make of changes in the larger university? Do our institutions stand in need of reform as much as, or more than, intercollegiate athletics?

\section{Issue \#3: Athletics and Education as Separate or Joined Together}

Speakers presented very different strategies for improving the athletic-academic relationship. Some espouse the more cautious route-one of building at least strategic "fire walls" so that powerful athletic interests in winning, for example, do not contaminate educational goals and conversely, that strong educational policies do not eviscerate healthy, crowd-pleasing competition. From this vantage point, walls make good neighbors. Others argue that reform is dependent more on mutual understanding and appreciation, if not the development of different visions of sport and education altogether. These objectives, arguably, can be achieved more easily if walls were taken down and athletics and education were brought closer together.

Which approach makes more sense? Can these two strategies actually be combined in creative ways? Is a root problem in all of this a certain parochial view of education and sport that unduly limits the former and misreads the latter? 


\section{Issue \#4: Athletics as Curricular, Cocurricular, or Extracurricular}

Speakers presented very different visions of athletics in relationship to the core educational values and activities of higher education. At one extreme, athletics is seen as an educational experience that could rival most others found in the formal curriculum. At the other, sport is portrayed as a diversion that has relatively little educational potential even under the best of conditions. Somewhere in the middle, intercollegiate sport is described as having an educational role to play but one that will never be fully realized under current conditions.

Is sport like other performance opportunities in our institutions, for instance like music, theater, or dance? Do not many of those programs mimic athletics in that students practice for countless hours, perform in front of paying audiences, become professionals in performance, and so on (Brand, 2006)? Or, on the contrary, are intercollegiate athletics and other performance activities disanalogous in important ways? Does a Sport College make academic sense, or is it an indefensible accommodation?

\section{Issue \#5: Reform as Useful, Futile, or Unnecessary}

A case can be made for all three of these positions, and our speakers in one way or another reflected these divergent conclusions. Some speakers emphasize what is good about college sport, not just potentially, but as it is conducted today. They argue that college sport is not a uniform phenomenon and that potential ills that might infect Division I athletics or a few high-visibility sports do not necessarily threaten the rest. Reform efforts in these situations would be superfluous. Others see reform as needed but largely as an exercise in futility. They point to past reform efforts and their meager results to support their position. Still others argue that times have changed, and they are ripe for reform. They point out that substantial progress has already been made on improving the overall educational experience for athletes, and more is yet to come.

In light of these diverse perspectives, do we need a multipronged approach, an acknowledgment in effect that "one size does not fit all"? Do past failures at reform stand as reliable bell-weathers for future efforts? If not, what current conditions suggest that things will be any different?

Enough. If one keeps asking questions like these for a sufficiently long period of time, a kind of intellectual vertigo will begin to infect all of us. Perhaps it is time to stop asking and begin reading and reflecting. I hope that you find the articles in this first issue of JIS as interesting, enlightening, and provocative as I did.

If it is "time to stop asking," it might also be time to start doing more and better research on intercollegiate athletics. In that regard, and speaking on behalf of the Board, I hope that all of you will join us at a future colloquium and that at least some of you will, in the near future, find your own research among the pages of the Journal of Intercollegiate Sport. 


\section{Notes}

1. JIS is not the only journal that publishes research on intercollegiate sport, but it is the first interdisciplinary publication, to my knowledge, that focuses exclusively on athletics in the context of higher education. Two other interdisciplinary journals that have a less specifically defined mission include the Journal for the Study of Sports and Athletes in Education (Left Coast Press) and Contemporary Athletics (Nova Publishers).

2. Many Board members, including myself, believe that an undergirding justification for both the Colloquium and the Journal is utility. This commitment is reflected in Jack Evans's reaction to Jay Coakley, in which he underlines the importance of putting research to work. Still, in our daily lives as people and scholars, curiosity often leads and utility follows.

3. It was only recently, in 2006, that Kinesiology was accepted as an NRC-rated discipline.

4. Simon raises these questions in his article included in this issue of JIS.

\section{References}

Bowen, W.G., \& Levin, S.A. (2003). Reclaiming the game: College sports and educational values. Princeton, NJ: Princeton University Press.

Brand, M. (2006). The role and value of intercollegiate athletics in universities. Journal of the Philosophy of Sport, XXXIII, 9-20.

Gould, S.J. (2003). The hedgehog, the fox, and the magister's pox. New York: Harmony Books.

Kretchmar, R.S. (2005). Practical philosophy of sport and physical activity (2nd ed.). Champaign, IL: Human Kinetics.

Shulman, J., \& Bowen, W.G. (2001). The game of life: College sports and educational values. Princeton, NJ: Princeton University Press.

Snow, C.P. (1959/1986). The two cultures and a second look. Cambridge, UK: Cambridge University Press.

Thelin, J.R. (1994). Games colleges play: Scandal and reform in intercollegiate athletics. Baltimore, MD: Johns Hopkins University Press. 